\title{
Organization Culture and Utilization of ICT in the Management of Internal Processes at Kenya Medical Training Colleges
}

\author{
Daniel Kipkulei Kimwetich ${ }^{1}$, James Mwikya Reuben ${ }^{2}$ \\ ${ }^{1,2}$ Management University of Africa \\ Nairobi, Kenya
}

\begin{abstract}
The purpose of the study was to study the influence of organizational culture on the utilization of information and communication technology (ICT) in the management of internal processes at Kenya Medical Training Colleges. The objective was to establish the influence of organizational culture on the utilization of ICT in the management of internal processes in Kenya Medical Training Colleges. The absorptive capacity theory anchored the variables of the present study. The researcher employed a descriptive research design. A systematic sampling procedure was used to settle on campuses. Purposive sampling was used to get the respondents who participated in the study. The study targeted all the staff who deals with the management of internal processes at Kenya Medical Training Colleges (KMTC) like the Principal, ICT personnel, finance manager, human resource, procurement officer and librarian. SurveyMonkey sample size online calculator tool was used to calculate the sample size. A sample size of 170 was used in the study from a target population of 390. Data was gathered from the field by use of self-administered questionnaires. Consent was sought verbally. The Crobach's index computed was 0.878 which indicated that the instrument was reliable. Collected data was verified. Results and findings of the study was analyzed using the statistical package for social sciences (SPSS) version 20.0 then presented using tables and figures. The overall aggregate mean score for the objective was 3.97 and the standard deviation was 0.869 . This on average affirmed that the respondents acknowledged that organizational culture was relevant and important to ensure that ICT is utilized in the management of internal processes at KMTC. The regression analysis results on the effect of organization culture on the utilization of ICT show $R=0.646$ indicating a positive correlation and $R 2=0.418$ and there was a significant effect between organization culture and utilization of ICT $(t=10.976, p<0.05)$. The study recommends that KMTC should establish systems for setting organizational culture as a tool to enhance the utilization of ICT. Furthermore, the utilization of ICT at the workplace ought to be promoted and daily management processes should be ICT based.
\end{abstract}

Key words: Organisation Culture, Utilization, Information, Communication Technology, Internal Processes, Kenya Medical Training College.

\subsection{INTRODUCTION}

Worldwide, the use of Information and Communication Technologies (ICT) has been on upward push and outstandingly has impacted greatly on the management of activities and processes in most sectors. ICT has been viewed to have the potential of rising education standards in most countries in the world [1]. ICT is an umbrella term that comprises any communication device or application, incorporating: radio, television (TV), mobile phone, computer, and connection hardware and software, satellite systems among others and the several services and uses related to these devices, for instance videoconferencing and distance learning. ICT has gained recognition not only in developed countries but also in developing countries. For example United State of America spends above \$10 Billion yearly in educational related technology in Public studying institutions [2].

In another case [3] observed that Australia spends around AUD\$8 billion in schooling related technological know-how related to ICT. The other incidence where a government has made considerable investments with aim of boasting ICT in the view of developing public education using modern technologies is Saudi Arabia, where the government invested nearly £2bn in reforming and improving education using modern technologies. In Saudi Arabia the governments' attempt to develop public education was achieved through revising of curriculum and introduction of electronic devices to facilitate teaching. The programme additionally made a provision for training and development applications for trainers to make sure they accumulate sufficient competencies in use of records technology in education zone. The government introduced programs for educators to ensure sufficient use of ICT in education [4]. 
Adoption of information communication technology in school management impacts the school management positively. ICT may improve school financial standards, academic standards and gain achievement in co-curriculum activities. Use of ICT in administration guide and strengthen internal processes in learning institutions. The ICT can be regarded as a catalyst in instructional use of technology in management [5].

In Africa, computer systems have been first used in different faculties in North Africa closer to the end of nineteen sixties commonly to facilitate management [6], whilst in late 1970s computers were used in training institutions particularly in learning. This was inspired by governments' need to initiate students to computers and introduce certain software programs.

Provision of ICT in learning institutions in Kenya is in line with the country's E-government and National Digital Strategies providing the foundation for dynamic E-education to be incorporated into Kenyan learning practice. As a result, there is a need to determine and uphold organization between all events concerned in the academic exercise to allow addressing of all ICT matters efficaciously [7].

According to [8], the most considerable difficulty in learning institution used to be ICT resources. Newhouse framework contends that resource availability or lack thereof is strongly linked to utilization of ICT. That, in turn, supports effects and offers logistics of how to provide, in terms of content, learning products and pedagogy in training institutions. Though, Newhouse framework additionally stresses the questioning of [9], which pointed out that the readiness of sources in the absence technical support makes ICT utilization challenging in incorporating its principles at faculty level. Newhouse used a systematic method with a view that all relations have effect on each other. For example, the availability of resources and technical support with lack of abilities or information to combine ICT in management activities will have no advantageous impact to the organization [8].

\subsection{Statement of the problem}

ICT is one main area of investment focused by governments' big four agenda and vision 2030. The Kenyan government has continued to invest heavily in ICT since the year 2007. Application of ICT in any field is perceived to have potentials of improving organization standards from a lower level to a high level.

Utilization of ICT in learning institution aids in the management of internal processes like in the following departments; accounts, procurement, accommodation, administration, and library. Medical colleges, particularly in the developed countries, have invested heavily in ICT for planning, organizing, leading, coordinating and controlling internal processes in order to deliver quality management of their institutions.

Reference [8] argued that the utilization of ICT in training institution is a vital solution to have an efficient management of internal processes. In addition, Newhouse questions the view of [9] for stressing that readiness of resources without good organizational culture makes it difficult to incorporate ICT in management. On the other hand Newhouse added that availability of resources and organization culture should go hand in hand with the abilities of the users and giving the correct information.

Consequently, [10] in some studies have identified various factors that explain the reluctance of the education sector to adopt and use ICTs. Peculiar challenges have previously curtailed the take up and superior use of ICT tools and that, these boundaries need to be overcome for the organization to progress, similarly in the utilization of ICTs to direct its business objectives. To this effect, some of the notable barriers such as lack of a coherent ICT strategy, Low ICT competencies and lack of resources especially in SMEs, reactive approach to ICT investment, differing demands from customers for systems and functionalities, switching costs related to replacing old systems with new integrated solutions has been cited.

Currently, management of internal processes at KMTC in accounts, procurement, accommodation, administration and library are done manually, yet huge investments have been done to equip these departments with computers and internet. Failure to adopt technology in the management of its internal processes will affect the services offered at KMTC and limit its ranking as a leading middle level training institution in Kenya. Therefore, this study sought to investigate influence of organization culture on utilization of ICT in the management of internal processes in Kenya Medical Training Colleges.

\subsection{General objective}

The main objective is to study influence of organization culture on utilization of ICT in management of internal processes in Kenya Medical Training Colleges. 


\title{
2.0 LITERATURE REVIEW
}

\subsection{Theoretical Literature Review}

This section brings out theory anchoring the study, which is the Absorptive Capacity theory which focuses on the social aspects of people and society and technical aspects of organizational structure and processes. The theory seeks to find out the types of rewards that are of importance to people.

\begin{abstract}
Absorptive Capacity Theory
Sociotechnical systems theory pertains to theory regarding the social aspects of people and society and technical aspects of organizational structure and processes. Here, technical does not necessarily imply material technology. The focus is on culture, procedures and related knowledge [11].
\end{abstract}

Absorptive Capacity Theory (ACT) is the ability to identify, assimilate, transform, and apply valuable external knowledge to the organization. In other words absorptive capacity is a limit to the rate or quantity of scientific or technological information that an organization can utilize. Absorptive capacity theory examines the extent to which an organization can recognize the value of new internal and external information, absorb it, and utilize it toward achieving set organizational goals. The theory assumes that absorbing new information can help an organization become more innovative and flexible and achieve higher levels of performance than it would without absorbing new information and knowledge e.g. ICT. The theory also takes into account that firms that have higher abilities for absorbing new culture and knowledge will have a competitive advantage over firms with lower abilities [12].

The term 'absorptive capacity theory' is used to highlight an organization's capability to assimilate, transform, and apply valuable external information and knowledge. The theory has gradually expanded in popularity and the term has been used widely at the organizational level to scrutinize innovation processes and the outcome of organizational knowledge on the establishment of sustainable competitive advantage for the institution. Absorptive capacity drives far beyond understanding the obvious things about the micro climate in which a company runs. Instead it takes a look the bigger picture at an industry and its reasonably competitive situation. It takes into cognizance all the factors that can affect change both for better or worse and allows an organization to truly understand its market position [13].

Reference [3] observed that an organization with high absorptive capacity is one with an outward-looking business strategy where staff, and especially managers, are encouraged to be explorative i.e. they gather knowledge from many different types of sources and not just the obvious. It has a pulse on what is happening in the market-place, and is able to utilize this broader insight to keep ahead of the competition. In the end, it puts a business on the fore front and equips them with the knowledge that will help them to understand their place in the competitive landscape, and to see opportunities in the political, economic, social, technological, environmental and legal factors that affect the entire universe of their business.

Reference [13] further extended the theory by specifying four distinct dimensions to absorptive capacity: acquisition, assimilation, transformation and exploitation. When absorption limits exist, they provide one explanation for firms to develop internal research capacities. Research departments can not only conduct development along lines they are already familiar with, but they have formal training and external professional connections that make it possible for them to evaluate and incorporate externally generated technical knowledge into the firm.

However, [14] seriously question Zahra and George's reconceptualization of absorptive capacity theory. During the last twenty years, organizations have been experiencing important changes brought about by the surge of the digital era. The information explosion is giving rise to a more intelligent world, and more intelligent companies with new organizational, competitive, and learning strategies. New information is created at a frenzied rate, the means to transform it into knowledge are more and more massive, and thus the possibility to continuously create new knowledge grows exponentially. This reality about organizational intelligence is being addressed with an excessive focus on technology with the development of new information management tools and strategic consultancy practices involved in massive information analysis, which is paving the way for organizations to be able to capture, store, and understand vast amounts of data Managing this massive information is key for the survival of a company in the changing, dynamic, global environment [15].

\subsection{Empirical Literature Review}

\subsubsection{Organization Culture and Utilization of ICT}

As per [16], most woe in management of companies are due to the gradual and cumbersome facts in organization culture, management processes, the lack of coverage on statistics administration in companies, and obstacles to the adoption of 
Information Technology (IT). One reason for the difficulty of implementing ICT is the misalignment of current organizational structures and cultures with ICT models for integrated and collaborative work environments. This is because the education sector is largely decentralized and composed of separate organizations, which must participate together on a project by project basis. The multi-participant, multi-organizational structure is a common obstacle in utilization of ICT in an organization [17].

According to the [7], unique obstacles such, organization culture, in the past restrained the take up and superior use of special ICT tools and that, these obstacles need to be overcome for the industry to develop in addition to the exploitation of ICTs to guide its enterprise activities. One reason for the difficulty of implementing ICT is the misalignment of current organizational structures and cultures with ICT models for integrated and collaborative work environments. The existence of an organization culture is important in utilization of ICT. There is no supporting data on the existence of a positive ICT organization culture at Kenya Medical Training Colleges (KMTC).

\subsection{Conceptual Framework}

The conceptual framework shows the relationship between the explained variables and explanatory variable. It brings out the association of the independent variable and their influence on Utilization of ICT at Kenya Medical Training Colleges.

Independent

Dependent

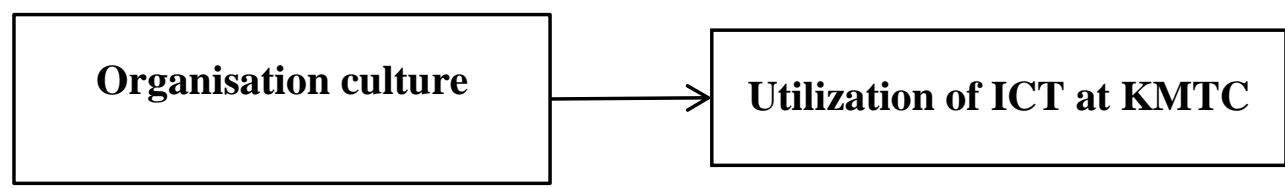

Figure 1: Conceptual framework

\subsection{RESEARCH DESIGN AND METHODOLOGY}

\subsection{Research design}

Reference [18] asserted that descriptive statistics allow significant explanation of measurements by use of minimal statistics. The researcher employed descriptive cross sectional research design to examine determinants of ICTs utilization in the Kenya Medical colleges.

\subsection{Target Population}

According to [19], a population is a group of individuals, events, or objects having common observable characteristics. The study targeted management staff in Kenya Medical Training Colleges. There are 65 campus of KMTC across the country. The staff personnel who deal with management of internal processes (principal, ICT personnel, finance manager, human resource, procurement officer and library) were targeted in each campus.

Table 1: Target population

\begin{tabular}{lc}
\hline Personnel & Number \\
\hline Principals & 65 \\
ICT in-charge & 65 \\
Finance Manager & 65 \\
Human Resource & 65 \\
Procurement Officer & 65 \\
Library In-charge & 65 \\
\hline Total & $\mathbf{3 9 0}$ \\
\hline
\end{tabular}

\subsection{Sample and sampling}

\section{technique}

Sampling includes the processes of enrolling sub-sets of a population to represent the whole population so as to gather the desired information pertaining to the subject matter [20]. Therefore, a sample refers to a section of a population symbolic of the whole population. This research employed systematic sampling procedures to settle on campuses. The study used purposive sampling to select respondents for this study in the sampled campuses. 
International Journal of Advances in Scientific Research and Engineering (ijasre), Vol 5 (11), November-2019

Table 2: Sampled population

\begin{tabular}{lcc}
\hline Personnel & Number & Sample \\
\hline Principals & 65 & 32 \\
ICT in-charge & 65 & 32 \\
Finance Manager & 65 & 33 \\
Human Resource & 65 & 32 \\
Procurement Officer & 65 & 33 \\
Library In-charge & 65 & 32 \\
\hline Total & $\mathbf{3 9 0}$ & $\mathbf{1 9 4}$ \\
\hline
\end{tabular}

\subsection{Data Collection Instrument}

According to [19] data collection can be referred to as the process of collecting and quantifying information on variables of concentration in a conventional systematic manner so as to allow the investigator to answer specified study questions. Data was gathered from the field by use of questionnaires. The questionnaires comprised of structured and unstructured questions.

\subsection{Pilot Study}

The pilot study targeted $10 \%$ of the total number of sampled population which came to 4 campuses [19]. Their responses were used to adjust the questionnaires so as to ensure that they contain the required data to answer the particular questions so as to address the research problem.

\subsection{Validity of the Data Collection Instrument}

Filled questionnaires were cross-checked for completeness and accuracy before being entered for analysis.

\subsection{Reliability Test}

Crobach alpha score of the instrument was obtained from the primary data. Crobachs alpha ranges between $0-1$. Scores between 00.6 indicate that the instrument has a low reliability, while scores of 0.7 and above indicate that the instrument has a high level of internal consistency and reliability [21]. The Crobachs index computed was 0.878 which indicated that the instrument was reliable.

\subsection{Data collection procedure}

Data collection is referred to as a process of gathering information from respondents or interviewees. This is done through the use of research instruments [22]. Prior to data collection, the researcher sought approval and a written permission to conduct research from the Management University of Africa. The researcher used a letter from the university to obtain a permit license from NACOSTI. The researcher then commenced the data collection using questionnaires. Two research assistants were inducted by the researcher on data collection procedures to help the researcher in the distribution and collection of questionnaires to and from all campuses. The principals in each of the sampled campuses assisted in sending back the filled questionnaires. The questionnaires were administered to the staff members who manage internal processes at Kenya Medical Training College. Both qualitative and quantitative data was collected from the Kenya Medical College staff. The data was collected by the researcher assisted by two research assistants.

\subsection{Data Analysis and Presentation}

The completed questionnaires were checked for completeness and consistency before processing the responses. The data was then coded to enable the responses to be grouped into various categories. Data collected was both quantitative and qualitative in nature. Analysis was done after data sorting using SPSS version 20.0. Descriptive statistics including mean and standard deviation helped the researcher to describe the data.

\subsection{RESULTS AND DISCUSSION}

\subsection{Response Rate}

There were a total of 170 questionnaires distributed to the target respondents. From this 170 respondents gave their responses in all the questions asked. Consequently, as seen in Table 3, the questionnaire response rate was $100 \%$ which is satisfactory and substantial going by [22] affirmations that a response rate that exceeds more than half is both acceptable and significant. 
International Journal of Advances in Scientific Research and Engineering (ijasre), Vol 5 (11), November-2019

Table 1: Response Rate of Respondents

\begin{tabular}{ccc}
\hline Response & Frequency & Percentage \\
\hline Returned & 170 & 100 \\
Unreturned & 0 & 0 \\
\hline Total & $\mathbf{1 7 0}$ & $\mathbf{1 0 0}$ \\
\hline
\end{tabular}

This acceptable response rate is a result of unwavering efforts by the researcher and research assistants who tirelessly kept in touch with the respondents and collected the dully filled questionnaires on time.

\subsection{Pilot Study Results}

The study conducted a pilot study to test the validity and reliability of the research instruments using the Cronbach's Alpha values for each variable and finally the overall items were used in the questionnaire. The respondents provided key information that was useful to modify the questionnaire thereby availing constructs that were valid [22]. The reliability results were enumerated as seen in Table 4.

Table 4: Reliability Test Results

\begin{tabular}{lccc}
\hline Variable & No of items & Pilot test & Crobach's Alpha \\
\hline Organization culture & 12 & 0.712 & 0.820 \\
\hline
\end{tabular}

\subsection{General Characteristics of Respondents}

The present study was primarily concerned with investigating the relationship between utilization of ICT and management of KMTC internal processes. Therefore, the respondents were requested to provide the study with demographic information as seen in the following results.

\subsection{Gender Distribution}

The gender of the target respondents (Departmental heads, teaching and non-teaching staff) was enumerated as seen in Table 5 .

Table 5: Gender distribution

\begin{tabular}{lcc}
\hline Class & Count & Percentage \\
\hline Male & 88 & 51.8 \\
Female & 82 & 48.2 \\
\hline Total & $\mathbf{1 7 0}$ & $\mathbf{1 0 0}$ \\
\hline
\end{tabular}

From the above table, it is evident that more than half of the respondents at $51.8 \%$ were male and $48.2 \%$ being female. This implies that KMTC staffing was male dominated, however, the female pool was not far behind. This is an encouraging implication particularly considering the fact that traditionally most organizations were male dominated. However, the trend indicates that female employees are increasing significantly hence gender equality in employment.

\subsection{Descriptive statistics}

\subsubsection{Organization Culture on Utilization of ICT}

The objective was to establish the influence of organization culture and utilization of ICT in the management of internal processes at KMTC. The summary of the results was shown in Table 6. The overall aggregate mean score for the objective was 3.97 and the standard deviation was 0.869 . This on average affirmed that the respondents acknowledged that organization culture was relevant to ensure employees utilized ICT on the job to manage internal processes, and this was ultimately aimed at improving organizational performance. This supported the statement suggesting that organization culture is boosted when students access communication online in the training institutions with the highest mean score of 4.25 and a standard deviation of 0.827 . The statement of 'KMTC apps are available' had the lowest mean score of 3.79 and a standard deviation of 0.905 . This implied that most of the respondents at KMTC did not experience any link between creating apps and organization culture. The results goes in line with one study which found that the organization nature of multi-participant and multi-organizational is a common obstacle in utilization of ICT in an organization since the people are diverse and come for different regions [23]. 
Table 6: Organization Culture

\begin{tabular}{|c|c|c|c|c|}
\hline & Minimum & Maximum & Mean & $\begin{array}{l}\text { Std. } \\
\text { Deviation }\end{array}$ \\
\hline Students can access official communication online & 2 & 5 & 4.25 & .827 \\
\hline Students can access learning materials online met & 2 & 5 & 4.22 & .860 \\
\hline $\begin{array}{l}\text { My daily activities at work place are } \\
\text { computerized/digitised }\end{array}$ & 2 & 5 & 4.16 & .899 \\
\hline $\begin{array}{l}\text { Management minimizes costs of operation by ICT } \\
\text { adoption }\end{array}$ & 2 & 5 & 4.13 & .907 \\
\hline ICT culture is promoted in all departments & 2 & 5 & 4.08 & .832 \\
\hline The organisation has kept up with changes in technology & 1 & 5 & 4.06 & .871 \\
\hline $\begin{array}{l}\text { There are policies in place to ensure continued growth in } \\
\text { Technology }\end{array}$ & 2 & 5 & 3.99 & .856 \\
\hline ICT is used in teaching and learning practices & 2 & 5 & 3.96 & .821 \\
\hline $\begin{array}{l}\text { ICT is used in management of KMTC } \\
\text { processes/activities }\end{array}$ & 2 & 5 & 3.96 & .809 \\
\hline Staff can access KMTC communications online & 2 & 5 & 3.95 & .858 \\
\hline Video-conferencing is utilized at KMTC & 1 & 5 & 3.80 & .983 \\
\hline KMTC apps are available & 2 & 5 & 3.79 & .905 \\
\hline Valid N (list wise) $=\mathbf{1 7 0}$ & & & & \\
\hline Aggregate Score & & & 3.97 & 0.869 \\
\hline
\end{tabular}

\section{Inferential statistics}

\subsection{Effect of organization culture on utilization of ICT.}

The study sought to investigate the effect of organization culture on utilization of ICT. Regression analysis (see table 7) was done with utilization of ICT as the dependent variable and organization culture as the predictor factor. The regression analysis revealed a relationship $\mathrm{R}=0.646$ which showed a strong positive correlation and revealed that organization culture and utilization of ICT are fundamentally related, and $\mathrm{R}^{2}=0.418$ which meant that $41.8 \%$ of variation in utilization of ICT can be explained by a unit change in organization culture.

Table 7: Table of fit for organization culture

\begin{tabular}{lcccc}
\hline \multicolumn{5}{c}{ Model Summary } \\
\hline Model & $\mathrm{R}$ & R Square & $\begin{array}{c}\text { Adjusted R } \\
\text { Square }\end{array}$ & $\begin{array}{c}\text { Std. Error of the } \\
\text { Estimate }\end{array}$ \\
\hline 1 & .646 & .418 & .414 & .52595 \\
\hline
\end{tabular}

The results agrees with a study by Price (2014) which found that organizational culture has been linked to the failure in the implementation of innovation in different organisations. The values of $F=120.476$ show that organization culture statistically and significantly affects utilization of ICT which means the regression model is a good fit of the data and that organization culture significantly influences the management of internal processes at KMTC. The level of significance is 0.000 which is less than 0.05 hence the regression model significantly predicts the dependent variable. The results were enumerated as seen in Table 8 .

Table 8: ANOVA ${ }^{\mathrm{a}}$ Results for Organization Culture

\begin{tabular}{lrrrrr}
\hline \multicolumn{5}{c}{ ANOVA $^{\mathbf{a}}$} \\
\hline Model & Sum of Squares & $\mathrm{df}$ & Mean Square & F & Sig. \\
\hline Regression & 33.326 & 1 & 33.326 & 120.476 & $.000^{\mathrm{b}}$ \\
Residual & 46.472 & 168 & .277 & & \\
Total & 79.798 & 169 & & \\
\hline
\end{tabular}

The study outcome indicated that introduction of organization culture to KMTC has a significant positive impact on utilization of ICT. The results indicate that there is significant relationship between organization culture and utilization of ICT; $p<0.05(\mathrm{P}=$ $0.01)$. Thus, the values of employee training are statistically significant $(t=10.976, p<.05)$ which means an increase in mean 
index of organization culture will increase utilization of ICT by a positive unit mean index value of 0.716 (71.6 percent). The regression model explaining the results enumerated in Table 9 is given by: Utilization of ICT $=0.964+0.716($ Organization Culture). The model shows that organization culture positively affects utilization of ICT in the management of internal processes at KMTC.

Table 9: Regression Coefficients for Organization Culture

\begin{tabular}{|c|c|c|c|c|c|c|c|}
\hline \multicolumn{8}{|c|}{ Coefficients $^{\mathrm{a}}$} \\
\hline \multirow[t]{2}{*}{ Model } & \multicolumn{2}{|c|}{$\begin{array}{c}\text { Unstandardized } \\
\text { Coefficients }\end{array}$} & \multirow{2}{*}{$\begin{array}{c}\text { Standardize } \\
\text { d } \\
\text { Coefficients } \\
\text { Beta }\end{array}$} & \multirow[t]{2}{*}{$\mathrm{T}$} & \multirow[t]{2}{*}{ Sig. } & \multicolumn{2}{|c|}{$\begin{array}{l}95.0 \% \text { Confidence } \\
\text { Interval for B }\end{array}$} \\
\hline & B & Std. Error & & & & $\begin{array}{l}\text { Lower } \\
\text { Bound }\end{array}$ & $\begin{array}{l}\text { Upper } \\
\text { Bound }\end{array}$ \\
\hline (Constant) & .964 & .266 & & 3.628 & .000 & .439 & 1.489 \\
\hline Total Org_Cul & .716 & .065 & .646 & 10.976 & .000 & .587 & .844 \\
\hline
\end{tabular}

\subsection{CONCLUSION}

The study established a significant positive relationship between organization culture and utilization of ICT. The study established and provided evidence that organization culture influence utilization of ICT in the management of internal processes at KMTC. Organization culture at workplace ought to be promoted and daily management of internal processes ought to be ICT based in order for a positive culture to be build.

\subsection{RECOMMENDATIONS}

The researchers recommend that KMTC should establish systems for setting organizational culture as a tool to enhance utilization of ICT.

\section{REFERENCE}

1. S. Noor-Ul-Amin, An effective use of ICT for education and learning by drawing on worldwide knowledge, research, and experience: ICT as a change agent for education. Scholarly Journal of Education, 2(4), 38-45, 2013.

2. J. D. Brunk, "Factors affecting the level of technology implementation by teachers in elementary schools". 190. The University of Oklahoma, 2008.

3. J. M. Lane, "Developing the vision: Preparing teachers to deliver a digital world-Class education system" Australian Journal of Teacher Education, vol.37, no.4, 2012, pp.59-74.

4. P. Tatweer, "King Abdullah bin Abdul-Aziz public educational development project" Tatweer project. Available from< http://www.tatweer.edu.sa/content/aboutus >. [12 Dec 2014].

5. S. Kumar, M. and M. Tammelin, Integrating ICT into language learning and teaching: Guide for institutions. Johannes Kepler Universität Linz, Altenberger Strape, 69, 4040, 2008.

6. R.E. Clark, and R.E. Meyor, Media in teaching. In M. C. Wittrock (Ed.) Handbook of research on teaching (3rd ed.), 2003, (pp. 464-478). New York: Macmillan.

7. K.A. Bingimlas, Barriers to the successful integration of ICT in teaching and learning environments: A review of the literature. Eurasia journal of mathematics, science \& technology education, 5(3), 2009.

8. P. Newhouse, Literature review: The impact of ICT on learning and teaching. Perth, Western Australia: Department of Education, 2002.

9. C.P. Lime, and M. Khine, Managing teachers' barriers to ICT integration in Singapore schools. Journal of technology and Teacher Education, 2002, 14(1), 97-125.

10. J. Ssewanyana, and M. Busler, Adoption and usage of ICT in developing countries: Case of Uganda firms. International Journal of Education and Development using ICT, 2007, 3(3), 49-59.

11. S. Sawyer, and M.H. Jarrahi, Sociotechnical Approaches to the Study of Information Systems. In A. Tucker, \& H. Topi (Eds.), Computing Handbook: Information systems and information technology, 3rd Edition, 2014, Boca Raton, FL: Taylor \& Francis.

12. W. Cohen and D. Levinthal, "Absorptive capacity: a new perspective on learning and innovation." Administrative Science Quarterly 35(1),1990, pp 128-152.

13. S.A. Zahra, and G. George, "Absorptive Capacity: A Review Reconceptualization, and Extension," Academy of Management Review (27:2), 2002, pp. 185-203.

14. G. Todorova and B. Durisin, "Absorptive Capacity: Valuing a Reconceptualization," Academy of Management Review (32:3), 2007, pp. 774-786. 
15. J. Cano Giner, Technology ecosystem governance. Organization Science, 25 (4), 2014, pp. 1195-1215. DOI: 10.1287/orsc.2014.0895.

16. R. Gyampoh-Vidogah, R. Moreton, and D. Proverbs, Implementing information management in construction: establishing problems, concepts and practice. Construction Innovation, 2003, 3(3), 157-173.

17. S. Yamnill, and G.N. McLean, Theories supporting transfer of training. Human resource development quarterly, 2001, 12(2), 195-208.

18. O.M. Mugenda, and A.G. Mugenda, Research Methods: Quantitative and Qualitative Approaches. Nairobi: Acts Press, 2008.

19. O.M. Mugenda, Research Methods: Quantitative and Qualitative Approaches. Nairobi: Acts Press, 2003.

20. F.N. Kerlinger, and H.B Lee, Survey research. Foundations of behavioral research, 599-619, 2003.

21. D.R. Cooper, P.S. Schindler, and J. Sun, Business Research Methods (Vol. 9), 2013, New York: McGraw-Hill Irwin.

22. O.M. Mugenda, and A.G. Mugenda, Research Methods: Quantitative and Qualitative Approaches. Nairobi: Acts Press, 1999.

23. J. Walters, Positive management. New York: Business Expert Press, 2010. 